\title{
Long-term quality-adjusted survival following therapeutic bronchoscopy for malignant central airway obstruction
}

\author{
Philip Ong, Horiana B Grosu, Labib Debiane, Roberto F Casal, George A Eapen, \\ Carlos A Jimenez, Laila Noor, David E Ost
}

\begin{abstract}
- Additional material is published online only. To view, please visit the journal online (http://dx.doi.org/10.1136/ thoraxjn-2018-211521).

Department of Pulmonary Medicine, The University of Texas MD Anderson Cancer Center, Houston, Texas, USA
\end{abstract}

\section{Correspondence to}

Dr David E Ost, Department of Pulmonary Medicine, The University of Texas MD Anderson Cancer Center, Houston, TX 77030, USA; dost@mdanderson.org

Received 12 January 2018 Revised 28 August 2018 Accepted 3 September 2018 Published Online First 25 September 2018

\section{Check for updates}

\section{(c) Author(s) (or their} employer(s)) 2019. No commercial re-use. See rights and permissions. Published by BMJ.

To cite: Ong P, Grosu HB, Debiane L, et al. Thorax 2019;74:141-156.

\begin{abstract}
Background While therapeutic bronchoscopy has been used to treat malignant central (CAO) airway obstruction for $>25$ years, there are no studies quantifying the impact of therapeutic bronchoscopy on long-term quality-adjusted survival.

Methods We conducted a prospective observational study of consecutive patients undergoing therapeutic bronchoscopy for CAO. Patients had follow-up at 1 week and monthly thereafter until death. Outcomes included technical success (ie, relief of anatomic obstruction), dyspnoea, health-related quality of life (HRQOL) and quality-adjusted survival.
\end{abstract}

Results Therapeutic bronchoscopy was performed on 102 patients with malignant CAO. Partial or complete technical success was achieved in $90 \%$ of patients. At 7 days postbronchoscopy, dyspnoea improved (mean $\triangle$ Borg-day- $7=-1.8,95 \% \mathrm{Cl}-2.2$ to $-1.3, p<0.0001$ ) and HRQOL improved (median prebronchoscopy 0.618 utiles, $25 \%-75 \%$ IQR 0.569 to 0.699 , mean $\Delta$ utility-day- $7+0.047$ utiles, $95 \% \mathrm{Cl}$ +0.023 to $0.071, p=0.0002$ ). Improvements in dyspnoea and HRQOL were maintained long-term. Compared with the prebronchoscopy baseline, HRQOL per day of life postbronchoscopy improved (mean $\Delta$ utilitylong-term +0.036 utiles, $95 \% \mathrm{Cl}+0.014$ to 0.057 , $\mathrm{p}=0.002$ ). Median quality-adjusted survival was 109 quality-adjusted life-days (QALDs) $(95 \%$ Cl 74 to 201 QALDs). Factors associated with longer quality-adjusted survival included better functional status, treatmentnaïve tumour, endobronchial disease, less dyspnoea, shorter time from diagnosis to bronchoscopy, absence of cardiac disease, bronchoscopic dilation and receiving chemotherapy.

Conclusions Therapeutic bronchoscopy improves HRQOL as compared with baseline, resulting in approximately a $5.8 \%$ improvement in HRQOL per day of life. The risk-benefit profile in these carefully selected patients was very favourable.

Trial registration number Results; NCT03326570.

Malignant central airway obstruction (CAO) occurs when tumours occlude the trachea, the main bronchi, the bronchus intermedius or a lobar bronchus. The clinical consequences of malignant CAO include dyspnoea and decreased health-related quality of life (HRQOL). Prior studies have demonstrated that therapeutic bronchoscopy for malignant CAO is associated with good short-term

\section{Key messages}

What is the key question?

- The long-term benefit of therapeutic bronchoscopy for malignant central airway obstruction has never been quantified in terms of quality-adjusted life-years (QALYs).

- Knowing the magnitude of the long-term benefits and what factors influence this are essential for patient management since it is central to risk-benefit assessments and determination of cost-effectiveness.

What is the bottom line?

- Therapeutic bronchoscopy results in a $5.8 \%$ improvement in health-related quality of life per day of life, which is roughly 1.5 times the benefit seen with treatment of malignant pleural effusions over the long-term.

Why read on?

- This manuscript quantifies the magnitude and variability of the impact of therapeutic bronchoscopy on patients with malignant central airway obstruction as measured in QALYs and identifies the factors that influence this; this information can help inform proper patient selection.

outcomes, as measured by relief of dyspnoea and improvements in HRQOL. ${ }^{1-14}$

However, while there is a single study looking at short-term changes in utility following therapeutic bronchoscopy, ${ }^{3}$ and there are studies of quality-adjusted survival in other areas of interventional pulmonology such as malignant pleural effusions ${ }^{15}$ and bronchoscopic treatments of emphysema, ${ }^{16}$ there are to our knowledge no long-term studies of quality-adjusted survival beyond 30 days in patient treated with therapeutic bronchoscopy for malignant CAO. Quality-adjusted survival, usually expressed as quality-adjusted life-years (QALYs), is essential for cost-effectiveness analysis and has been recognised as the most important indicator of the effectiveness of healthcare interventions, as reflected by the guidelines of the National Institute of Health and Clinical Excellence, the US Public Health Service and the Agency for Healthcare Research and Quality. ${ }^{17-21}$ 


\begin{tabular}{|c|c|}
\hline & $\begin{array}{l}\text { Number of patients }(\%) \\
\mathrm{N}=102\end{array}$ \\
\hline Mean age (years) & $63.2 \pm 11.2$ \\
\hline \multicolumn{2}{|l|}{ Gender } \\
\hline Male & $65(64 \%)$ \\
\hline Female & $37(36 \%)$ \\
\hline \multicolumn{2}{|l|}{ Race } \\
\hline Asian & $3(3 \%)$ \\
\hline Black & $11(11 \%)$ \\
\hline Hispanic & $11(11 \%)$ \\
\hline White & $76(75 \%)$ \\
\hline Other & $1(1 \%)$ \\
\hline \multicolumn{2}{|l|}{ Smoking history } \\
\hline Current or prior & $71(70 \%)$ \\
\hline Never & $31(30 \%)$ \\
\hline Baseline Zubrod (median, IQR) & 1 (1 to 2$)$ \\
\hline ASA score (median, IQR) & 3 (3 to 3$)$ \\
\hline Baseline utility (median, IQR) & 0.618 (0.569 to 0.699$)$ \\
\hline Baseline Borg (median, IQR) & 3.5 (2 to 5$)$ \\
\hline $\begin{array}{l}\text { Weeks from cancer diagnosis to procedure } \\
\text { (median, IQR) }\end{array}$ & 75 (7 to 252$)$ \\
\hline \multicolumn{2}{|l|}{ Urgency of procedure } \\
\hline Elective & $81(79 \%)$ \\
\hline Urgent & $4(4 \%)$ \\
\hline Emergent & $17(17 \%)$ \\
\hline \multicolumn{2}{|l|}{ Comorbidities* } \\
\hline Asthma & $3(3 \%)$ \\
\hline COPD & $14(14 \%)$ \\
\hline Cardiovascular & $26(26 \%)$ \\
\hline Diabetes & $24(24 \%)$ \\
\hline Second primary solid tumour & $11(11 \%)$ \\
\hline Increased bleeding risk & $1(1 \%)$ \\
\hline \multicolumn{2}{|l|}{ Cancer type } \\
\hline Lung & $44(43 \%)$ \\
\hline Breast & $3(3 \%)$ \\
\hline Colon & $1(1 \%)$ \\
\hline Oesophageal & $5(5 \%)$ \\
\hline Renal & $19(19 \%)$ \\
\hline Sarcoma & $3(3 \%)$ \\
\hline Other solid tumour & $23(23 \%)$ \\
\hline Haematological malignancy & $4(4 \%)$ \\
\hline \multicolumn{2}{|l|}{ Initial cancer treatment } \\
\hline Surgery & $38(37 \%)$ \\
\hline Chemotherapy & $27(27 \%)$ \\
\hline Radiation therapy & $13(13 \%)$ \\
\hline No treatment & $24(24 \%)$ \\
\hline Prior therapeutic bronchoscopy & $8(8 \%)$ \\
\hline \multicolumn{2}{|l|}{ Indication(s) for therapeutic bronchoscopy* } \\
\hline Tracheoesophageal fistula & $4(4 \%)$ \\
\hline Haemoptysis & $21(21 \%)$ \\
\hline Malignant central airway obstruction & $102(100 \%)$ \\
\hline $\begin{array}{l}\text { Number of bronchopulmonary segments } \\
\text { obstructed (median, IQR) }\end{array}$ & 10 (8 to 18 ) \\
\hline
\end{tabular}

Continued
Table 1 Continued

\begin{tabular}{|c|c|}
\hline & $\begin{array}{l}\text { Number of patients }(\%) \\
\mathrm{N}=102\end{array}$ \\
\hline \multicolumn{2}{|l|}{$\begin{array}{l}\text { Location of most proximal airway } \\
\text { obstruction }>50 \%\end{array}$} \\
\hline Trachea & $23(23 \%)$ \\
\hline Bilateral main stem & $7(7 \%)$ \\
\hline Right main bronchus & $28(28 \%)$ \\
\hline Left main bronchus & $18(18 \%)$ \\
\hline Bronchus intermedius & $11(11 \%)$ \\
\hline Lobar only & $15(15 \%)$ \\
\hline \multicolumn{2}{|l|}{ Obstruction type } \\
\hline Endobronchial & $64(63 \%)$ \\
\hline Extrinsic & $27(27 \%)$ \\
\hline Mixed & $11(11 \%)$ \\
\hline \multicolumn{2}{|l|}{ Procedural methods } \\
\hline \multicolumn{2}{|l|}{ Type of ventilation } \\
\hline Jet ventilation & $93(91 \%)$ \\
\hline Volume cycled & $9(9 \%)$ \\
\hline \multicolumn{2}{|l|}{ Type of bronchoscopy } \\
\hline Flexible only & $8(8 \%)$ \\
\hline Rigid and flexible (vs flexible only) & $94(92 \%)$ \\
\hline \multicolumn{2}{|l|}{ Treatment modalities used } \\
\hline YAP laser & $17(17 \%)$ \\
\hline Electrocautery (snare, probe or forceps) & $32(31 \%)$ \\
\hline Argon plasma coagulation & $64(63 \%)$ \\
\hline Cryorecanalisation & $21(21 \%)$ \\
\hline Microdebrider & $26(25 \%)$ \\
\hline Rigid 'coring' & $11(11 \%)$ \\
\hline Dilation & $20(20 \%)$ \\
\hline $\begin{array}{l}\text { Stent present on completion of first } \\
\text { procedure }\end{array}$ & $34(33 \%)$ \\
\hline \multicolumn{2}{|l|}{ Stent type placed at first procedure $(n=34)$} \\
\hline Aero & $22(65 \%)$ \\
\hline Ultraflex & $2(6 \%)$ \\
\hline Silicone tube & $1(4 \%)$ \\
\hline Y-Stent & $9(26 \%)$ \\
\hline \multicolumn{2}{|l|}{ Technical success (airway open $>50 \%$ ) } \\
\hline Complete & $68(67 \%)$ \\
\hline Partial & $23(23 \%)$ \\
\hline Failed & $11(11 \%)$ \\
\hline \multicolumn{2}{|l|}{ Postprocedure treatment } \\
\hline Surgery & $4(4 \%)$ \\
\hline Chemotherapy & $60(59 \%)$ \\
\hline Radiation therapy & $57(56 \%)$ \\
\hline
\end{tabular}

*Patients could have one or more comorbidities, so each comorbidity is dichotomous. For bronchoscopy indication, patients could have more than one indication for bronchoscopy, but one of them had to be for malignant central airway obstruction.

The goal of this study was to quantify long-term quality-adjusted survival following therapeutic bronchoscopy for malignant CAO. Our secondary objective was to identify factors associated with quality-adjusted survival. Our hypothesis was that therapeutic bronchoscopy would result in sustained significant longterm improvements in utility and dyspnoea as compared with baseline. 
Table 2 Factors associated with change in dyspnoea (Borg score day-7 minus Borg baseline)*

\begin{tabular}{|c|c|c|c|c|c|c|c|c|c|}
\hline & \multicolumn{3}{|l|}{ Univariate } & \multicolumn{3}{|c|}{ Multivariate predictive } & \multicolumn{3}{|c|}{ Multivariate explanatory } \\
\hline & Coefficient & $95 \% \mathrm{Cl}$ & $P$ values & Coefficient & $95 \% \mathrm{Cl}$ & $P$ values & Coefficient & $95 \% \mathrm{Cl}$ & $P$ values \\
\hline \multicolumn{10}{|l|}{ Predictive variables } \\
\hline Age & 0.01 & -0.03 to 0.05 & 0.53 & & & & & & \\
\hline Male gender & 0.63 & -0.27 to 1.53 & 0.17 & & & & & & \\
\hline Zubrod $2-4$ vs $0-1$ & -0.21 & -1.08 to 0.67 & 0.64 & & & & & & \\
\hline Baseline utility & 1.04 & -2.27 to 4.35 & 0.54 & & & & & & \\
\hline Baseline Borg & -0.53 & -0.66 to -0.40 & $<0.001$ & -0.53 & -0.66 to -0.40 & $<0.001$ & -0.52 & -0.64 to -0.40 & $<0.001$ \\
\hline $\begin{array}{l}\text { Urgent/emergent vs } \\
\text { elective }\end{array}$ & -0.21 & -1.31 to 0.89 & 0.71 & & & & & & \\
\hline $\begin{array}{l}\text { Time from diagnosis to } \\
\text { procedure (weeks) }\end{array}$ & 0 & -0.002 to 0.002 & 0.89 & & & & & & \\
\hline \multicolumn{10}{|l|}{ Comorbidities } \\
\hline COPD & -0.42 & -1.70 to 0.86 & 0.52 & & & & & & \\
\hline Cardiovascular & -0.35 & -1.36 to 0.66 & 0.49 & & & & & & \\
\hline Diabetes & -0.21 & -1.23 to 0.82 & 0.69 & & & & & & \\
\hline $\begin{array}{l}\text { Second primary solid } \\
\text { tumour }\end{array}$ & 0.79 & -0.64 to 2.21 & 0.28 & & & & & & \\
\hline \multicolumn{10}{|l|}{ Cancer type } \\
\hline Lung & 0.32 & -0.57 to 1.20 & 0.48 & & & & & & \\
\hline Other malignancies & $<$ ref $>$ & & & & & & & & \\
\hline \multicolumn{10}{|l|}{ Initial treatment type } \\
\hline Surgery & -0.34 & -1.47 to 0.79 & 0.55 & & & & & & \\
\hline Chemotherapy & -0.58 & -1.82 to 0.65 & 0.35 & & & & & & \\
\hline Radiation therapy & -0.93 & -2.55 to 0.70 & 0.26 & & & & & & \\
\hline No treatment & $<$ ref $>$ & & & & & & & & \\
\hline $\begin{array}{l}\text { Any prior therapeutic } \\
\text { bronchoscopy }\end{array}$ & 1.78 & 0.23 to 3.32 & 0.02 & & & & & & \\
\hline \multicolumn{10}{|l|}{$\begin{array}{l}\text { Indication(s) for } \\
\text { therapeutic bronchoscopy }{ }^{\prime}\end{array}$} \\
\hline $\begin{array}{l}\text { Tracheoesophageal } \\
\text { fistula }\end{array}$ & -0.05 & -2.19 to 2.08 & 0.96 & & & & & & \\
\hline Haemoptysis & 0.61 & -0.47 to 1.69 & 0.26 & & & & & & \\
\hline $\begin{array}{l}\text { Number of } \\
\text { bronchopulmonary } \\
\text { segments obstructed }\end{array}$ & -0.05 & -0.13 to 0.04 & 0.29 & & & & & & \\
\hline \multicolumn{10}{|l|}{$\begin{array}{l}\text { Location of most proximal } \\
\text { obstruction }\end{array}$} \\
\hline Trachea & -0.83 & -2.32 to 0.66 & 0.27 & & & & & & \\
\hline Bilateral mainstem & -0.86 & -2.85 to 1.14 & 0.40 & & & & & & \\
\hline Right mainstem & -1.15 & -2.57 to 0.27 & 0.11 & & & & & & \\
\hline Left mainstem & -0.91 & -2.47 to 0.65 & 0.25 & & & & & & \\
\hline $\begin{array}{l}\text { Right bronchus } \\
\text { intermedius }\end{array}$ & -0.25 & -2.04 to 1.54 & 0.78 & & & & & & \\
\hline Lobar only & $<\mathrm{ref}>$ & & & & & & & & \\
\hline \multicolumn{10}{|l|}{$\begin{array}{l}\text { Obstruction type of most } \\
\text { proximal location }\end{array}$} \\
\hline Endobronchial & $<$ ref $>$ & & & & & & & & \\
\hline Extrinsic & 0.41 & -0.61 to 1.42 & 0.43 & & & & & & \\
\hline Mixed & 0.71 & -0.83 to 2.24 & 0.36 & & & & & & \\
\hline \multicolumn{10}{|l|}{ Explanatory variables } \\
\hline \multicolumn{10}{|l|}{ Ventilation type } \\
\hline Jet ventilation & 0.02 & -1.48 to 1.53 & 0.97 & & & & & & \\
\hline
\end{tabular}


Table 2 Continued

\begin{tabular}{|c|c|c|c|c|c|c|c|c|c|}
\hline & \multicolumn{3}{|l|}{ Univariate } & \multicolumn{3}{|c|}{ Multivariate predictive } & \multicolumn{3}{|c|}{ Multivariate explanatory } \\
\hline & Coefficient & $95 \% \mathrm{Cl}$ & $P$ values & Coefficient & $95 \% \mathrm{Cl}$ & $P$ values & Coefficient & $95 \% \mathrm{Cl}$ & $P$ values \\
\hline Volume cycled & $<$ ref $>$ & & & & & & & & \\
\hline \multicolumn{10}{|l|}{ Bronchoscopy type } \\
\hline Rigid and flexible & 0.27 & -1.32 to 1.85 & 0.74 & & & & & & \\
\hline Flexible only & $<$ ref $>$ & & & & & & & & \\
\hline \multicolumn{10}{|l|}{ Treatment modalities } \\
\hline Any laser & -0.58 & -1.73 to 0.56 & 0.31 & & & & & & \\
\hline Electrocautery & -0.41 & -1.34 to 0.52 & 0.39 & & & & & & \\
\hline Argon plasma & 0.62 & -0.27 to 1.51 & 0.17 & & & & & & \\
\hline Cryorecanalisation & -1.29 & -2.09 & 0.02 & & & & -1.1 & -1.88 to -0.32 & 0.007 \\
\hline Microdebrider & -0.63 & -1.60 to 0.35 & 0.21 & & & & & & \\
\hline Rigid 'coring' & -0.58 & -1.96 to 0.79 & 0.40 & & & & & & \\
\hline Dilation & 0.68 & -0.41 to 1.77 & 0.22 & & & & & & \\
\hline Stent at first procedure & 0.07 & -0.87 to 1.00 & 0.89 & & & & & & \\
\hline \multicolumn{10}{|l|}{ Stent type placed } \\
\hline Aero & -0.45 & -1.97 to 1.07 & 0.55 & & & & & & \\
\hline Y-Stent & 0.22 & -1.40 to 1.84 & 0.79 & & & & & & \\
\hline \multicolumn{10}{|l|}{ Technical success } \\
\hline Complete or partial & -0.49 & -1.87 to 0.88 & 0.48 & & & & & & \\
\hline Failed & $<\mathrm{ref}>$ & & & & & & & & \\
\hline \multicolumn{10}{|l|}{ Postprocedure treatment } \\
\hline Surgery & 0.66 & -1.50 to 2.82 & 0.55 & & & & & & \\
\hline Chemotherapy & 0.08 & -0.81 to 0.96 & 0.86 & & & & & & \\
\hline Radiation therapy & 0.36 & -0.52 to 1.23 & 0.43 & & & & & & \\
\hline
\end{tabular}

${ }^{*}$ Day-7 Borg score is 7 days after the study entry bronchoscopy. If the patient had subsequent bronchoscopies, these were not included in this analysis.

tPatients could have one or more comorbidities, so each comorbidity is dichotomous. For bronchoscopy indication, patients could have more than one indication for bronchoscopy, but one of them had to be for malignant central airway obstruction.

\section{METHODS}

This was a single-centre prospective observational study of consecutive patients undergoing therapeutic bronchoscopy for malignant central CAO from 1 September 2011 to 17 June 2014. Informed consent was obtained from all patients. Data were entered using definitions and quality control checks as previously described for the AQuIRE database but the data were captured using REDCap electronic data capture tools hosted at the University of Texas MD Anderson Cancer Center. ${ }^{22-25}$

Patients undergoing therapeutic flexible or rigid bronchoscopy for malignant CAO were included. CAO was defined as occlusion $\geq 50 \%$ of the trachea, mainstem bronchi, bronchus intermedius or lobar bronchus. Patients had systematic follow-up at 1 week, 1 month and monthly thereafter and were followed until death. Outcomes included: technical success (ie, relief of anatomic obstruction), dyspnoea, HRQOL/quality-adjusted survival and survival time.

Technical success was defined as reopening the airway lumen to $>50 \%$ of normal. If all stenotic airways were reopened this was considered complete success. If one or more occluded airways were reopened but any segment remained occluded this was classified as partial success. If no airways were reopened this was classified as failure. Dyspnoea was measured using the Borg score. HRQOL was measured using the SF-6D as previously described. ${ }^{26}$ The SF-6D provides a means to estimate a preference-based single index measure for health using general population data (see online supplement). Single index measures such as the SF-6D generate measures of utility for particular health states that range from 0 to 1 utiles. Zero utiles represents death and one is perfect health. Quality-adjusted survival can be thought of as the area under the curve with utility on the vertical axis and time on the horizontal axis. We express quality-adjusted survival in quality-adjusted life-days (QALDs). Since the focus was on long-term outcomes and quality-adjusted survival, we report complications in the online supplement using the AQuIRE registry definitions. ${ }^{27}$

\section{Statistical analysis}

To assess the short-term impact of therapeutic bronchoscopy on HRQOL and dyspnoea, we used paired t-tests to compare baseline versus day 7 utilities (derived from SF-6D) and Borg scores. Day 7 measured from the study entry bronchoscopy. We used a generalised linear model to identify variables associated with these outcomes. The dependent variable was the pairwise difference between day 7 postprocedure scores and baseline values ( $\Delta$ utility-day-7 for HRQOL and $\Delta$ Borg-day-7 for dyspnoea). We conducted a responder analysis for these outcomes as well (see online supplement).

The primary outcome was quality-adjusted survival and HRQOL. Long-term quality-adjusted survival was expressed as QALDs. We used a previously described method to calculate QALDs for each patient (see online supplement). ${ }^{15}$ The last observation carried forward (LOCF) method was specified a priori 
for imputation of missing utility measures. A secondary analysis used subsequent observations to impute missing utility measures (ie, carrying backward). There was no significant difference between results, so we report LOCF results. The Kaplan-Meier product-limit method was used to estimate median QALDs. Patients lost to follow-up or alive at study completion were censored. Cox proportional hazards models were fit to determine the association of variables with quality-adjusted survival (see online supplement). Time-varying covariates were not used for this outcome.

To compare HRQOL over the long-term versus baseline, we defined each patient's mean HRQOL per day of life postbronchoscopy as that patient's QALD/survival time. This represents the patient's time-weighted mean utility experienced postbronchoscopy-so what was that patient's utility on an average day. We calculated the long-term change in utility ( $\Delta$ utility-long-term)

A

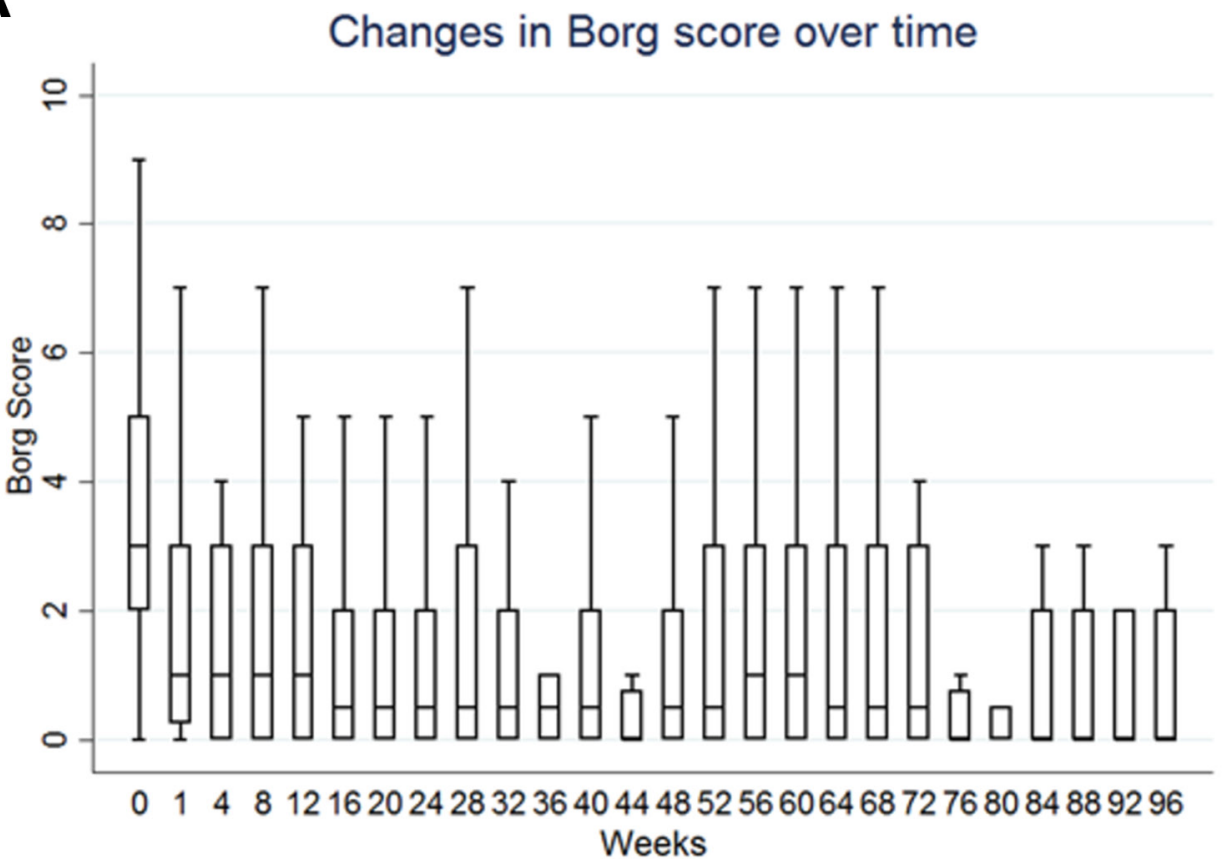

B
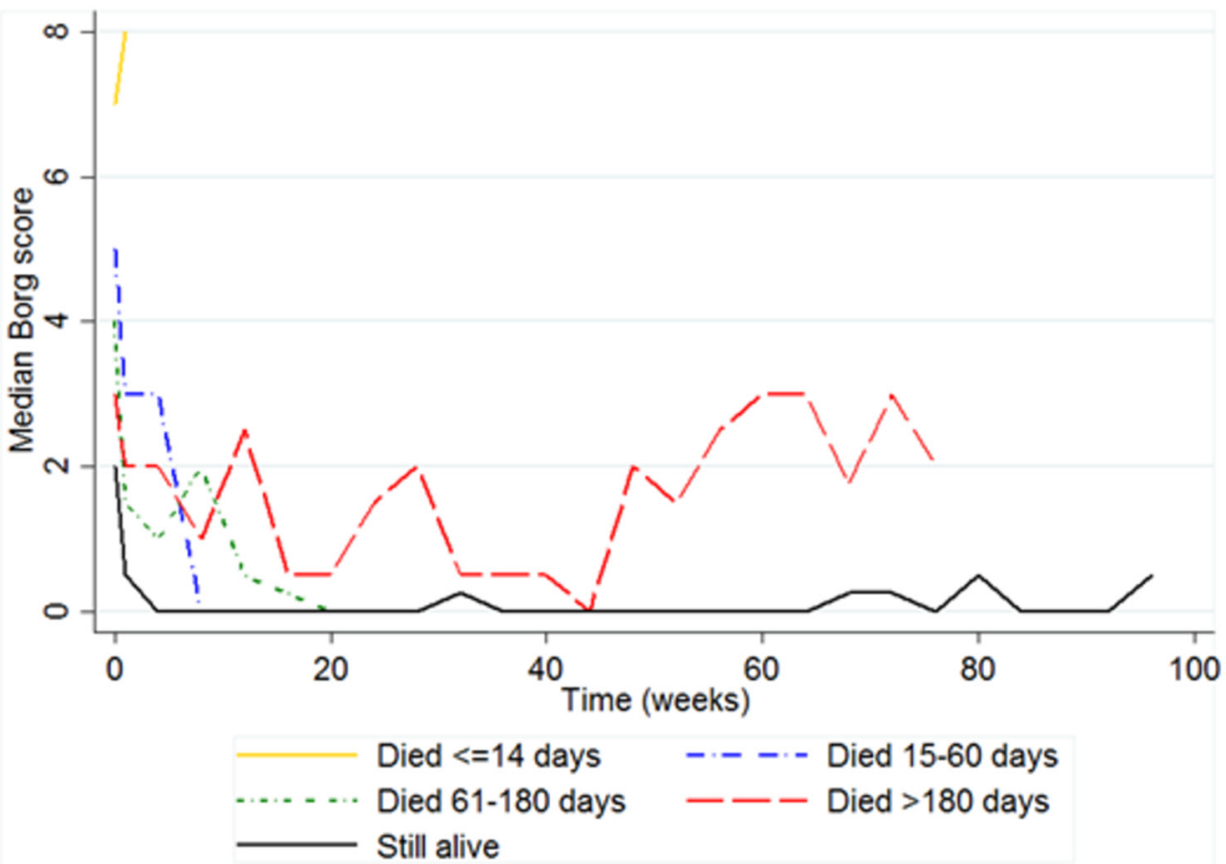

Figure 1 Changes in dyspnoea over time for the entire cohort. (A) Boxes represent medians and IQR of Borg scores among patients alive at that time point. Note that as patients die, they no longer contribute, so median dyspnoea of those alive appears to increase (ie, sick patients with dyspnoea die and no longer contribute data as we move to the right). To adjust for this, we can stratify by survivor group (bottom panel). (B) Median Borg scores over time by survivor group. 
by subtracting each patient's baseline utility from their mean HRQOL per day of life postbronchoscopy. We recognise that this is not a perfect measure of therapeutic impact, since patients who develop new clinical problems postbronchoscopy that are non-lethal could live a long time with lower utility, which would tend to drag down $\Delta$ utility long-term. We therefore also plotted utility over time stratified by survival duration $(<14,15-60$, 61-180, 181+ days).

For time to death, we used extended Cox models with time-dependent covariates to represent repeated measures such as utility and Borg scores as well as clinical events such as lower respiratory tract infections (see online supplement).

For multivariate models, all variables that had a p value $<0.20$ on univariate analyses were considered as candidate variables. In the absence of data on important predictors, we used backward selection to retain only variables whose $\mathrm{p}$ values were $<0.05$. P values $<0.05$ were considered to be significant; all tests were two-sided. Predictive models used only information available preprocedure, explanatory models used all available information.

Sample size was based on HRQOL. Assuming a baseline utility of 0.690 utiles and an improvement in utility to 0.723 utiles following therapeutic bronchoscopy with an SD of the difference of 0.1 , then to have $90 \%$ power to demonstrate a difference of +0.033 utiles with an alpha of 0.05 requires 99 patients. ${ }^{3}$ We estimate $10 \%$ of patients that consented would prove to have lesions that were not amenable to bronchoscopic intervention, so enrolment was capped at 110 patients. All statistical analyses were performed using STATA V.14.2 (StataCorp, College Station, Texas, USA).

\section{RESULTS}

\section{Patients}

A total of 102 patients had interventions. Baseline characteristics are shown in table 1. Partial or complete technical success was achieved in $90 \%$ of patients (see online supplement). Of the 102 patients, 75 died during the study period, 8 were eventually lost to follow-up (censored) and 17 were alive at study completion (censored). There were 915 scheduled follow-up measurements for dyspnoea (Borg) and utility (SF-6D) (average 9 measurements of each per patient). Follow-up data were missing in 159 (17\%) time points. Of the 102 patients, 61 had one or more missing follow-up data points.

\section{Impact on dyspnoea}

Of the 102 patients, 96 had baseline Borg scores, one was on a ventilator, two were emergent, three were missed. The analysis for dyspnoea was based on these 96 patients. Therapeutic bronchoscopy resulted in a significant improvement in dyspnoea at 7 days post the study entry bronchoscopy (mean $\Delta$ Borg-day- $7=-1.8$, $95 \% \mathrm{CI}-2.2$ to $-1.3, \mathrm{p}<0.0001)$. Note that lower scores indicate less dyspnoea, so if $\Delta$ Borg-day- 7 is negative dyspnoea decreased. In the multivariate predictive model, higher baseline Borg was associated with greater improvements in dyspnoea (table 2). A one unit increase in baseline Borg was associated with a 0.53 unit decrease in $\Delta$ Borg-day- $7(p<0.001)$.

In a responder analysis, 58 of 96 patients $(60 \%)$ had a clinically significant improvement in dyspnoea, 34 (35\%) stayed the same and $4(4 \%)$ worsened. In the predictive multivariate responder analysis, only higher baseline Borg $(\mathrm{p}<0.001)$ was associated with a clinically significant improvement in dyspnoea (see online supplement e-table 1). In the explanatory multivariate responder analysis, higher baseline Borg, receiving prior cancer treatment and use of the microdebrider were associated with clinically significant improvement in dyspnoea.

This improvement in dyspnoea was sustained over time for most patients (figure 1A). Patients who died within 14 days of bronchoscopy $(n=4)$ did not experience dyspnoea relief. For most patients, dyspnoea initially dramatically improved and this was maintained for most of their lives (figure 1B). In some patients, towards the end of life, there was a recurrence of dyspnoea.

\section{Impact on HRQOL}

HRQOL improved from prebronchoscopy to postbronchoscopy (median prebronchoscopy 0.618 utiles, 25\%-75\% IQR 0.569 to 0.699 ; mean $\Delta$ utility-day- $7+0.047$ utiles, $95 \%$ CI $+0.023-$ $0.071, \mathrm{p}=0.0002$ ). In multivariate predictive analysis, higher baseline Borg score, not having COPD and having no prior therapeutic bronchoscopies were associated with higher $\Delta$ utility-day-7 (ie, more benefit) (table 3). In explanatory multivariate analysis, greater improvements in dyspnoea (ie, more negative $\triangle$ Borg-day-7), not having COPD and having no prior therapeutic bronchoscopies were associated with higher $\Delta$ utility-day-7. A one unit increase in $\Delta$ Borg-day-7 (ie, more dyspnoea) resulted in a decrease in $\Delta$ utility-day-7 of 0.021 utiles $(p<0.001)$.

In a responder analysis, 51 of the 102 patients $(50 \%)$ had a clinically significant improvement in utility at 7 days, 33 (32\%) stayed the same and 18 (18\%) worsened (see online supplement e-table 2). In a multivariate predictive analysis, only having fewer lung segments occluded $(\mathrm{p}=0.05)$ was associated with having a clinically significant improvement in dyspnoea. In an explanatory multivariate analysis, older age $(p=0.03)$, greater improvements in dyspnoea $(\mathrm{p}=0.01)$ and not having COPD $(p=0.03)$ were associated with having a clinically significant improvement in dyspnoea.

Median quality-adjusted survival was 109 QALDs (95\% CI 74 to 201 QALDs). In a predictive multivariate Cox model (table 4), factors associated with longer quality-adjusted survival included better functional status, treatment-naïve tumour, endobronchial disease and less dyspnoea at baseline. In an explanatory multivariate Cox model, these same factors were associated with longer quality-adjusted survival. In addition, shorter time from cancer diagnosis to therapeutic bronchoscopy, absence of cardiac disease, bronchoscopic dilation and receiving chemotherapy postintervention were associated with longer quality-adjusted survival.

Given that therapeutic bronchoscopy is primarily palliative, long-term impact on HRQOL per day of life is an important measure. Median postbronchoscopy HRQOL per day of life was 0.655 utiles per day (25\%-75\% IQR 0.590 to 0.741 ). Compared with the prebronchoscopy baseline, HRQOL per day of life postbronchoscopy improved (mean $\Delta$ utility-long-term +0.036 utiles, $95 \% \mathrm{CI}+0.014$ to $0.057, \mathrm{p}=0.002)$. Evaluating utility changes over time stratified by survivor group (figure 2), we can see that for most survivor groups the gains in utility postbronchoscopy were maintained for some time, but as patients near the end of their lives utility starts to decrease, which in turn drags down HRQOL per day of life. Patients that died within 14 days $(n=4)$ were the exception; these patients had very low functional status to begin with and did not experience meaningful gains in utility. But for the majority, the immediate gains in utility postbronchoscopy were maintained for a significant amount of time.

In multivariate predictive analysis (table 5), factors associated with greater $\Delta$ utility-long-term included higher baseline Borg score and having fewer lung segments occluded. In a multivariate 
Table 3 Factors associated with change in utility (utility at day-7 minus baseline)*

\begin{tabular}{|c|c|c|c|c|c|c|c|c|c|}
\hline & \multicolumn{3}{|l|}{ Univariate } & \multicolumn{3}{|c|}{ Multivariate predictive } & \multicolumn{3}{|c|}{ Multivariate explanatory } \\
\hline & Coefficient & $95 \% \mathrm{Cl}$ & $P$ values & Coefficient & $95 \% \mathrm{Cl}$ & $P$ values & Coefficient & $95 \% \mathrm{Cl}$ & $P$ values \\
\hline \multicolumn{10}{|l|}{ Predictive variables } \\
\hline Age & 0.001 & -0.001 to 0.003 & 0.52 & & & & & & \\
\hline Male gender & 0.01 & -0.04 to 0.06 & 0.70 & & & & & & \\
\hline Zubrod 2-4 vs 0-1 & 0.036 & -0.012 to 0.084 & 0.14 & & & & & & \\
\hline Baseline utility & -0.014 & -0.198 to 0.170 & 0.88 & & & & & & \\
\hline Baseline Borg & 0.013 & 0.004 to 0.023 & 0.01 & 0.012 & 0.002 to 0.022 & 0.015 & & & \\
\hline Urgent/emergent vs elective & 0.02 & -0.12 & 0.51 & & & & & & \\
\hline $\begin{array}{l}\text { Time from diagnosis to procedure } \\
\text { (weeks) }\end{array}$ & -0.0001 & -0.0002 to 0.0001 & 0.41 & & & & & & \\
\hline \multicolumn{10}{|l|}{ Comorbidities } \\
\hline COPD & -0.048 & -0.118 to 0.023 & 0.18 & -0.079 & -0.150 to -0.008 & 0.03 & -0.069 & -0.136 to -0.002 & 0.05 \\
\hline Cardiovascular & 0.015 & -0.041 to 0.071 & 0.59 & & & & & & \\
\hline Diabetes & 0.036 & -0.021 to 0.093 & 0.21 & & & & & & \\
\hline Second primary solid tumour & -0.058 & -0.136 to 0.020 & 0.14 & & & & & & \\
\hline \multicolumn{10}{|l|}{ Cancer type } \\
\hline Lung & 0.02 & -0.028 to 0.070 & 0.40 & & & & & & \\
\hline Other malignancies & $<$ ref $>$ & & & & & & & & \\
\hline \multicolumn{10}{|l|}{ Initial treatment type } \\
\hline Surgery & 0.007 & -0.057 to 0.070 & 0.84 & & & & & & \\
\hline Chemotherapy & 0.016 & -0.052 to 0.085 & 0.65 & & & & & & \\
\hline Radiation therapy & 0.04 & -0.044 to 0.124 & 0.35 & & & & & & \\
\hline No treatment & $<$ ref $>$ & & & & & & & & \\
\hline $\begin{array}{l}\text { Any prior therapeutic } \\
\text { bronchoscopy }\end{array}$ & -0.125 & -0.211 to -0.039 & 0.01 & -0.111 & -0.199 to -0.023 & 0.02 & -0.102 & -0.186 to -0.018 & 0.02 \\
\hline \multicolumn{10}{|l|}{$\begin{array}{l}\text { indication(s) for therapeutic } \\
\text { bronchoscopy } \dagger\end{array}$} \\
\hline Tracheoesophageal fistula & -0.074 & -0.198 to 0.050 & 0.24 & & & & & & \\
\hline Haemoptysis & 0.007 & -0.052 to 0.067 & 0.81 & & & & & & \\
\hline $\begin{array}{l}\text { Number of bronchopulmonary } \\
\text { segments obstructed }\end{array}$ & -0.002 & -0.006 to 0.002 & 0.34 & & & & & & \\
\hline \multicolumn{10}{|l|}{$\begin{array}{l}\text { Location of most proximal } \\
\text { obstruction }\end{array}$} \\
\hline Trachea & -0.019 & -0.099 to 0.061 & 0.65 & & & & & & \\
\hline Bilateral mainstem & -0.002 & -0.114 to 0.110 & 0.97 & & & & & & \\
\hline Right mainstem & 0.048 & -0.030 to 0.126 & 0.22 & & & & & & \\
\hline Left mainstem & 0.026 & -0.058 to 0.110 & 0.55 & & & & & & \\
\hline Right bronchus intermedius & 0.019 & -0.077 to 0.115 & 0.70 & & & & & & \\
\hline Lobar only & $<$ ref $>$ & & & & & & & & \\
\hline \multicolumn{10}{|l|}{$\begin{array}{l}\text { Obstruction type of most proximal } \\
\text { location }\end{array}$} \\
\hline Endobronchial & $<$ ref $>$ & & & & & & & & \\
\hline Extrinsic & -0.025 & -0.082 to 0.032 & 0.39 & & & & & & \\
\hline Mixed & -0.008 & -0.105 to 0.055 & 0.85 & & & & & & \\
\hline \multicolumn{10}{|l|}{ Explanatory variables } \\
\hline$\Delta$ Borg & -0.023 & -0.024 & $<0.001$ & & & & -0.021 & -0.033 to -0.009 & $<0.001$ \\
\hline \multicolumn{10}{|l|}{ Ventilation type } \\
\hline Jet ventilation & 0.015 & -0.065 to 0.095 & 0.72 & & & & & & \\
\hline Volume cycled & $<$ ref $>$ & & & & & & & & \\
\hline \multicolumn{10}{|l|}{ Bronchoscopy type } \\
\hline Rigid and flexible & 0.006 & -0.084 to 0.096 & 0.89 & & & & & & \\
\hline Flexible only & $<$ ref $>$ & & & & & & & & \\
\hline
\end{tabular}


Table 3 Continued

\begin{tabular}{|c|c|c|c|c|c|c|c|c|c|}
\hline & \multicolumn{3}{|l|}{ Univariate } & \multicolumn{3}{|c|}{ Multivariate predictive } & \multicolumn{3}{|c|}{ Multivariate explanatory } \\
\hline & Coefficient & $95 \% \mathrm{Cl}$ & $P$ values & Coefficient & $95 \% \mathrm{Cl}$ & $P$ values & Coefficient & $95 \% \mathrm{Cl}$ & $P$ values \\
\hline Any laser & 0.037 & -0.028 to 0.102 & 0.26 & & & & & & \\
\hline Electrocautery & 0.047 & -0.004 to 0.098 & 0.07 & & & & & & \\
\hline Argon plasma & 0.025 & -0.024 to 0.074 & 0.33 & & & & & & \\
\hline Cryorecanalisation & 0.076 & 0.019 to 0.133 & 0.01 & & & & & & \\
\hline Microdebrider & -0.015 & -0.070 to 0.040 & 0.61 & & & & & & \\
\hline Rigid 'coring' & 0.068 & -0.008 to 0.144 & 0.08 & & & & & & \\
\hline Dilation & -0.064 & -0.123 to -0.005 & 0.04 & & & & & & \\
\hline Stent at first procedure & -0.031 & -0.082 to 0.020 & 0.23 & & & & & & \\
\hline \multicolumn{10}{|l|}{ Stent type placed } \\
\hline Aero & 0.003 & -0.075 to 0.081 & 0.94 & & & & & & \\
\hline Y-Stent & 0.018 & -0.064 to 0.100 & 0.66 & & & & & & \\
\hline \multicolumn{10}{|l|}{ Technical success } \\
\hline Complete or partial & 0.003 & -0.075 to 0.081 & 0.94 & & & & & & \\
\hline Failed & $<$ ref $>$ & & & & & & & & \\
\hline \multicolumn{10}{|l|}{ Postprocedure treatment } \\
\hline Surgery & -0.097 & -0.220 to 0.026 & 0.13 & & & & & & \\
\hline Chemotherapy & -0.002 & -0.051 to 0.047 & 0.93 & & & & & & \\
\hline Radiation therapy & 0.01 & -0.039 to 0.059 & 0.69 & & & & & & \\
\hline
\end{tabular}

explanatory analysis, higher baseline Borg score, having fewer lung segments occluded and $\Delta$ utility-day-7 were associated with a higher $\Delta$ utility-long-term. In univariate explanatory analysis, $59 \%$ of the observed variability in $\Delta$ utility-long-term was explained by the linear relationship between $\Delta$ utility-long-term and $\Delta$ utility-day-7 (ie, adjusted $\mathrm{R}^{2}=0.59$ ).

\section{Survival}

Median survival was 179 days (95\% CI 107 to 271). The factors associated with survival in the predictive Cox model (table 6) were the same as those associated with quality-adjusted survival. When we limited the explanatory model to the same covariates as used for quality-adjusted survival, the factors identified were again largely the same as with quality-adjusted survival. The one difference was that cardiovascular disease was associated with decreased survival but not associated with decreased quality-adjusted survival.

We then built extended Cox models to assess the impact of variables that vary over time on survival, such as lower respiratory tract infections, dyspnoea, HRQOL and whether or not a stent was in place (table 7). Taking into consideration these timevarying covariates, we found better baseline performance status as measured by Zubrod, higher HRQOL (utility) and receiving chemotherapy following therapeutic bronchoscopy were associated with improved survival. Conversely, lower respiratory tract infections were associated with increased mortality risk.

\section{DISCUSSION}

Therapeutic bronchoscopy for malignant CAO is essentially a palliative intervention. While therapeutic bronchoscopy may extend life in some patients with malignant CAO, such as those on mechanical ventilation due to $\mathrm{CAO}$, for the majority of patients the goal is relief of dyspnoea and improvement in HRQOL. In deciding whether therapeutic bronchoscopy is likely to benefit a given patient, it is therefore necessary to consider the probability of technical success, the magnitude of the impact that technical success is likely to have on dyspnoea, whether or not that benefit is likely to be maintained over time and how that in turn will impact long-term HRQOL and quality-adjusted survival. The potential benefits in long-term HRQOL must then be weighed against the risks of intervention. To the best of our knowledge, this study is the first to quantify long-term quality-adjusted survival following therapeutic bronchoscopy for malignant $\mathrm{CAO}$ and to identify the factors associated with it. Median quality-adjusted survival was 109 QALDs (95\% CI 74 to 201 QALDs). Factors associated with improved quality-adjusted survival included better baseline performance status, less dyspnoea at baseline, having a treatment-naïve tumour, endobronchial disease, shorter time from cancer diagnosis to intervention and receiving follow-up chemotherapy. Therapeutic bronchoscopy resulted in immediate improvements in dyspnoea and utility. Importantly, these improvements over baseline were maintained long-term such that HRQOL per day of life improved compared with prebronchoscopy levels.

Previous investigators have demonstrated improvements in dyspnoea and quality of life. ${ }^{1-14}$ However, these prior studies cannot fully inform clinical decision making because the benefits of intervention must be weighed against the risks but the trade-offs involved have different units. ${ }^{3}$ For example, how much risk does technical success warrant, when technical success is measured in relief of luminal narrowing and risk might be measured as pneumothorax or death? Dyspnoea is a more relevant patient-centred outcome, but how much risk of death does a clinically significant one unit change in Borg score warrant?

So benefit needs to be quantified in units that allow physicians to compare the benefits with the risks involved. This requires use of generic single-index measures of HRQOL such as the SF-6D that can be used to generate utilities (see the online supplement). The AQuIRE registry study of therapeutic bronchoscopy was the first to do this for short-term outcomes, reporting a mean baseline 
Lung cancer

Table 4 Factors associated with quality-adjusted survival time

\begin{tabular}{|c|c|c|c|c|c|c|c|c|c|}
\hline & \multicolumn{3}{|c|}{ Univariate } & \multicolumn{3}{|c|}{ Multivariate predictive } & \multicolumn{3}{|c|}{ Explanatory } \\
\hline & $\mathrm{HR}^{*}$ & $95 \% \mathrm{Cl}$ & $P$ values & $\mathrm{HR}^{*}$ & $95 \% \mathrm{Cl}$ & $P$ values & $\mathrm{HR}^{*}$ & $95 \% \mathrm{Cl}$ & $P$ values \\
\hline \multicolumn{10}{|l|}{ Predictive variables } \\
\hline Age & 0.998 & 0.98 to 1.02 & 0.87 & & & & & & \\
\hline Male gender & 0.73 & 0.46 to 1.16 & 0.18 & & & & & & \\
\hline Zubrod $2-4$ vs $0-1$ & 3.64 & 2.26 to 5.87 & $<0.001$ & 3.67 & 2.14 to 6.29 & $<0.001$ & 5.07 & 2.83 to 9.1 & $<0.001$ \\
\hline Urgent/emergent vs elective & 1.57 & 0.92 to 2.66 & 0.1 & & & & & & \\
\hline $\begin{array}{l}\text { Time from diagnosis to } \\
\text { procedure (weeks) }\end{array}$ & 1 & 1.00 to 1.00 & 0.18 & & & & 0.998 & 0.996 to 0.9997 & 0.02 \\
\hline Baseline Borg & 1.16 & 1.07 to 1.25 & $<0.001$ & 1.13 & 1.03 to 1.24 & 0.008 & 1.12 & 1.02 to 1.23 & 0.02 \\
\hline Baseline utility & 2.25 & 0.43 to 11.73 & 0.34 & & & & & & \\
\hline \multicolumn{10}{|l|}{ Comorbiditiest } \\
\hline COPD & 0.79 & 0.4 to 1.54 & 0.49 & & & & & & \\
\hline Cardiovascular & 1.57 & 0.95 to 2.6 & 0.08 & & & & 1.97 & 1.04 to 3.74 & 0.038 \\
\hline Diabetes & 0.84 & 0.48 to 1.46 & 0.54 & & & & & & \\
\hline Second primary & 1.29 & 0.64 to 2.6 & 0.48 & & & & & & \\
\hline \multicolumn{10}{|l|}{ Cancer type } \\
\hline Lung & 0.93 & 0.59 to 1.46 & 0.75 & & & & & & \\
\hline Other malignancies & $<$ ref $>$ & & & & & & & & \\
\hline \multicolumn{10}{|l|}{ Initial treatment type } \\
\hline Surgery & 1.43 & 0.75 to 2.72 & 0.28 & 2.13 & 1.03 to 4.4 & 0.04 & 4.74 & 1.98 to 11.36 & $<0.001$ \\
\hline Chemotherapy & 2.81 & 1.44 to 5.46 & 0.002 & 3.42 & 1.6 to 7.27 & 0.004 & 3.87 & 1.77 to 8.45 & 0.001 \\
\hline Radiation therapy & 2.34 & 1.06 to 5.2 & 0.04 & 2.21 & 0.92 to 5.3 & 0.07 & 2.1 & 0.87 to 5.08 & 0.1 \\
\hline No treatment & $<$ ref $>$ & & & $<$ ref $>$ & & & $<$ ref $>$ & & \\
\hline $\begin{array}{l}\text { Any prior therapeutic } \\
\text { bronchoscopy }\end{array}$ & 0.3 & 0.1 to 0.97 & 0.04 & & & & & & \\
\hline \multicolumn{10}{|l|}{$\begin{array}{l}\text { Indication(s) for therapeutic } \\
\text { bronchoscopyt }\end{array}$} \\
\hline Tracheoesophageal fistula & 1.27 & 0.4 to 4.04 & 0.69 & & & & & & \\
\hline Haemoptysis & 0.61 & 0.34 to 1.11 & 0.11 & & & & & & \\
\hline $\begin{array}{l}\text { Number of bronchopulmonary } \\
\text { segments obstructed }\end{array}$ & 1.06 & 1.01 to 1.11 & 0.02 & & & & & & \\
\hline \multicolumn{10}{|l|}{$\begin{array}{l}\text { Location of most proximal } \\
\text { obstruction }\end{array}$} \\
\hline Trachea & 1.6 & 0.76 to 3.36 & 0.22 & & & & & & \\
\hline Bilateral mainstem & 2.1 & 0.77 to 5.72 & 0.15 & & & & & & \\
\hline Right mainstem & 1.01 & 0.48 to 2.11 & 0.98 & & & & & & \\
\hline Left mainstem & 0.74 & 0.33 to 1.68 & 0.47 & & & & & & \\
\hline Right bronchus intermedius & 0.96 & 0.4 to 2.31 & 0.92 & & & & & & \\
\hline Lobar only & $<r e f>$ & & & & & & & & \\
\hline \multicolumn{10}{|l|}{$\begin{array}{l}\text { Obstruction type of most } \\
\text { proximal location }\end{array}$} \\
\hline Endobronchial & $<$ ref $>$ & & & $<$ ref $>$ & & & $<$ ref $>$ & & \\
\hline Extrinsic & 2.15 & 1.29 to 3.57 & 0.003 & 2.8 & 1.6 to 4.88 & $<0.001$ & 2.88 & 1.61 to 5.12 & $<0.001$ \\
\hline Mixed & 3.8 & 1.91 to 7.59 & $<0.001$ & 2.13 & 0.97 to 4.68 & 0.06 & 1.66 & 0.71 to 3.86 & 0.24 \\
\hline \multicolumn{10}{|l|}{ Explanatory variables } \\
\hline \multicolumn{10}{|l|}{ Ventilation type } \\
\hline Jet ventilation & 1.86 & 0.75 to 4.6 & 0.18 & & & & & & \\
\hline Volume cycled & 0.64 & 0.28 to 1.48 & 0.3 & & & & & & \\
\hline \multicolumn{10}{|l|}{ Bronchoscopy type } \\
\hline Rigid and flexible & 1.23 & 0.53 to 2.83 & 0.63 & & & & & & \\
\hline Flexible only & $<$ ref $>$ & & & & & & & & \\
\hline \multicolumn{10}{|l|}{ Treatment modalities } \\
\hline Any laser & 0.48 & 0.24 to 0.97 & 0.04 & & & & & & \\
\hline
\end{tabular}




\section{Lung cancer}

\begin{tabular}{|c|c|c|c|c|c|c|c|c|c|}
\hline & \multicolumn{3}{|c|}{ Univariate } & \multicolumn{3}{|c|}{ Multivariate predictive } & \multicolumn{3}{|c|}{ Explanatory } \\
\hline & $H R^{*}$ & $95 \% \mathrm{Cl}$ & $P$ values & $\mathrm{HR}^{*}$ & $95 \% \mathrm{Cl}$ & $P$ values & $\mathrm{HR}^{*}$ & $95 \% \mathrm{Cl}$ & $P$ values \\
\hline Electrocautery & 0.62 & 0.37 to 1.04 & 0.07 & & & & & & \\
\hline Argon plasma & 0.9 & 0.57 to 1.42 & 0.65 & & & & & & \\
\hline Cryorecanalisation & 0.69 & 0.38 to 1.25 & 0.22 & & & & & & \\
\hline Microdebrider & 0.72 & 0.42 to 1.23 & 0.22 & & & & & & \\
\hline Rigid 'coring' & 0.77 & 0.37 to 1.6 & 0.48 & & & & & & \\
\hline Dilation & 1.57 & 0.91 to 2.7 & 0.1 & & & & 2.21 & 1.16 to 4.19 & 0.02 \\
\hline Stent at first procedure & 2.27 & 1.44 to 3.59 & $<0.001$ & & & & & & \\
\hline \multicolumn{10}{|l|}{ Stent type placed } \\
\hline Aero & 1.23 & 0.52 to 2.95 & 0.64 & & & & & & \\
\hline Y-Stent & 0.74 & 0.3 to 1.86 & 0.52 & & & & & & \\
\hline \multicolumn{10}{|l|}{ Technical success } \\
\hline Complete or partial & 0.64 & 0.32 to 1.29 & 0.21 & & & & & & \\
\hline Failed & $<$ ref $>$ & & & & & & & & \\
\hline \multicolumn{10}{|l|}{ Postprocedure treatment } \\
\hline Chemotherapy & 0.88 & 0.56 to 1.38 & 0.58 & & & & 0.44 & 0.26 to 0.74 & 0.002 \\
\hline Radiation therapy & 0.52 & 0.33 to 0.83 & 0.01 & & & & & & \\
\hline
\end{tabular}

${ }^{*}$ Higher HR represents an increased risk for shorter quality-adjusted survival.

tPatients could have one or more comorbidities, so each comorbidity is dichotomous. For therapeutic bronchoscopy indication(s), patients could have more than one indication for bronchoscopy, but one of them had to be for malignant central airway obstruction.
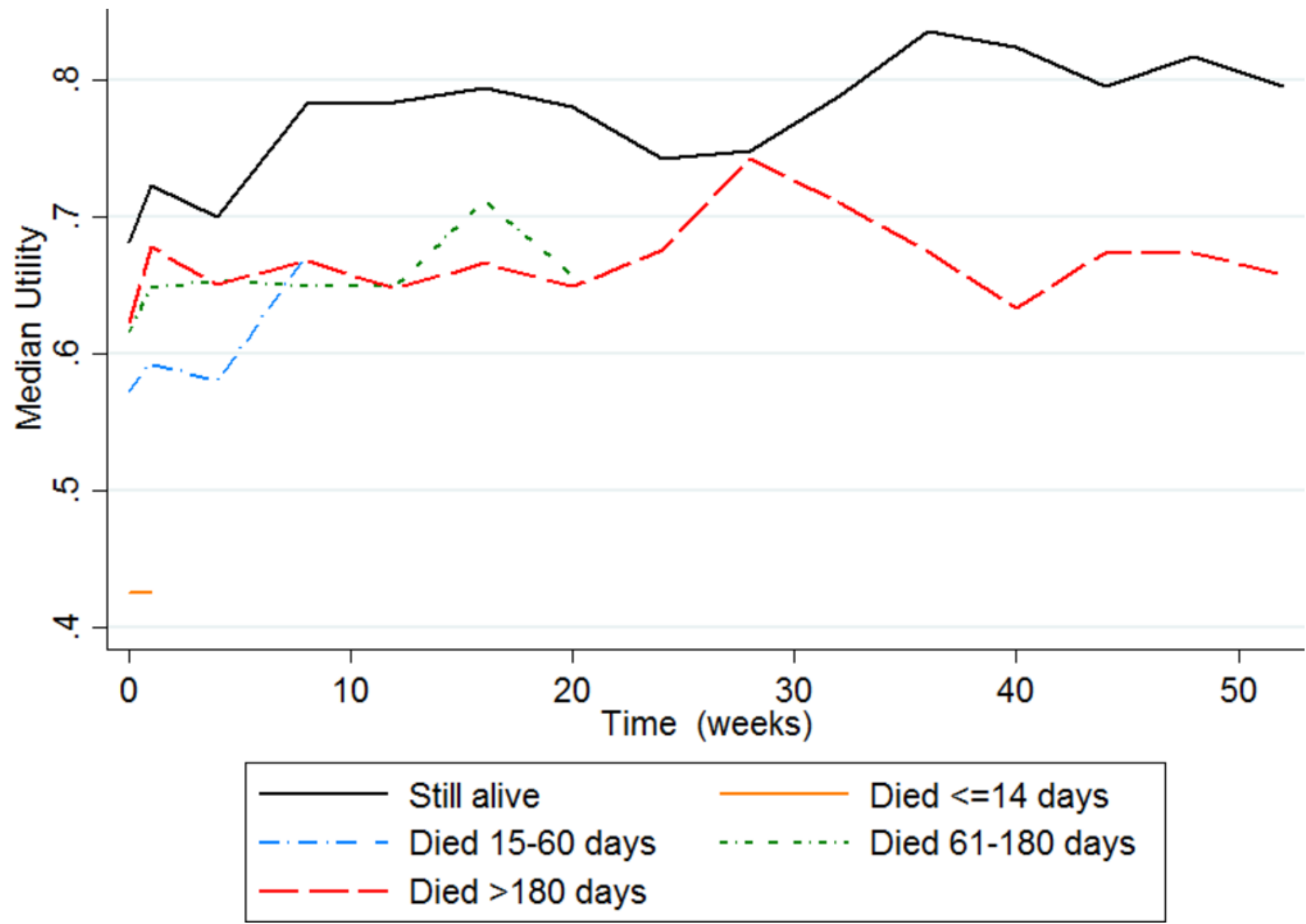

Figure 2 Changes in median utility over time by survivor group. 
Table 5 Factors associated with mean benefit per day of life measured in utility

\begin{tabular}{|c|c|c|c|c|c|c|c|c|c|}
\hline & \multirow[b]{2}{*}{ Coefficient } & \multicolumn{2}{|l|}{ Univariate } & \multicolumn{3}{|c|}{ Multivariate predictive } & \multicolumn{3}{|c|}{ Multivariate explanatory } \\
\hline & & $95 \% \mathrm{Cl}$ & $P$ values & Coefficient & $95 \% \mathrm{Cl}$ & $P$ values & Coefficient & $95 \% \mathrm{Cl}$ & $P$ values \\
\hline \multicolumn{10}{|l|}{ Predictive variables } \\
\hline Age & 0 & -0.002 to 0.002 & 0.94 & & & & & & \\
\hline Male gender & -0.008 & -0.053 to 0.037 & 0.71 & & & & & & \\
\hline Zubrod 2-4 vs 0-1 & 0.009 & -0.034 to 0.052 & 0.69 & & & & & & \\
\hline Baseline utility & -0.478 & -0.596 to -0.360 & $<0.001^{*}$ & & & & & & \\
\hline Baseline Borg & 0.019 & 0.011 to 0.027 & $<0.001$ & 0.022 & 0.014 to 0.030 & $<0.001$ & 0.012 & 0.007 to 0.018 & $<0.001$ \\
\hline Urgent/emergent vs elective & 0.026 & -0.027 to 0.079 & 0.33 & & & & & & \\
\hline $\begin{array}{l}\text { Time from diagnosis to } \\
\text { procedure (weeks) }\end{array}$ & -0.00006 & $\begin{array}{l}-0.00017 \text { to } \\
0.00005\end{array}$ & 0.77 & & & & & & \\
\hline \multicolumn{10}{|l|}{ Comorbidities } \\
\hline COPD & 0.009 & -0.054 to 0.073 & 0.77 & & & & & & \\
\hline Cardiovascular & 0.002 & -0.048 to 0.053 & 0.92 & & & & & & \\
\hline Diabetes & 0.027 & -0.024 to 0.079 & 0.29 & & & & & & \\
\hline Second primary solid tumour & -0.016 & -0.087 to 0.054 & 0.65 & & & & & & \\
\hline \multicolumn{10}{|l|}{ Cancer type } \\
\hline Lung & 0.028 & -0.016 to 0.072 & 0.21 & & & & & & \\
\hline Other malignancies & $<\mathrm{ref}>$ & & & & & & & & \\
\hline \multicolumn{10}{|l|}{ Initial treatment type } \\
\hline Surgery & -0.016 & -0.069 to 0.038 & 0.57 & & & & & & \\
\hline Chemotherapy & -0.019 & -0.077 to 0.039 & 0.52 & & & & & & \\
\hline Radiation therapy & 0.015 & -0.057 to 0.086 & 0.68 & & & & & & \\
\hline No treatment & $<$ ref $>$ & & & & & & & & \\
\hline $\begin{array}{l}\text { Any prior therapeutic } \\
\text { bronchoscopy }\end{array}$ & -0.087 & -0.16 to -0.007 & 0.03 & & & & & & \\
\hline \multicolumn{10}{|l|}{$\begin{array}{l}\text { Indication(s) for therapeutic } \\
\text { bronchoscopy* }\end{array}$} \\
\hline Tracheoesophageal fistula & -0.064 & -0.176 to 0.048 & 0.26 & & & & & & \\
\hline Haemoptysis & 0.009 & -0.045 to 0.063 & 0.73 & & & & & & \\
\hline $\begin{array}{l}\text { Number of bronchopulmonary } \\
\text { segments obstructed }\end{array}$ & -0.003 & -0.007 to 0.001 & 0.20 & -0.006 & -0.010 to -0.002 & 0.006 & -0.003 & -0.006 to -0.0002 & 0.036 \\
\hline \multicolumn{10}{|l|}{$\begin{array}{l}\text { Location of most proximal } \\
\text { obstruction }\end{array}$} \\
\hline Trachea & -0.027 & -0.010 to 0.045 & 0.46 & & & & & & \\
\hline Bilateral mainstem & -0.047 & -0.146 to 0.053 & 0.36 & & & & & & \\
\hline Right mainstem & 0.032 & -0.038 to 0.101 & 0.37 & & & & & & \\
\hline Left mainstem & -0.023 & -0.099 to 0.053 & 0.55 & & & & & & \\
\hline Right bronchus intermedius & 0.026 & -0.060 to 0.094 & 0.55 & & & & & & \\
\hline Lobar only & $<$ ref $>$ & & & & & & & & \\
\hline \multicolumn{10}{|l|}{$\begin{array}{l}\text { Obstruction type of most } \\
\text { proximal location }\end{array}$} \\
\hline Endobronchial & $<$ ref $>$ & & & & & & & & \\
\hline Extrinsic & -0.043 & -0.093 to 0.007 & 0.09 & & & & & & \\
\hline Mixed & -0.031 & -0.102 to 0.040 & 0.39 & & & & & & \\
\hline \multicolumn{10}{|l|}{ Explanatory variables } \\
\hline$\Delta$ Borg at day-7 & -0.023 & -0.035 to -0.011 & $<0.001$ & & & & & & \\
\hline$\Delta$ Utility at day-7 & 0.693 & 0.581 to 0.805 & $<0.001$ & & & & 0.612 & 0.498 to 0.725 & $<0.001$ \\
\hline \multicolumn{10}{|l|}{ Ventilation type } \\
\hline Jet ventilation & -0.005 & -0.078 to 0.069 & 0.90 & & & & & & \\
\hline Volume cycled & $<$ ref $>$ & & & & & & & & \\
\hline \multicolumn{10}{|l|}{ Bronchoscopy type } \\
\hline Rigid and flexible & -0.019 & -0.100 to 0.062 & 0.65 & & & & & & \\
\hline Flexible only & $<r e f>$ & & & & & & & & \\
\hline
\end{tabular}




\begin{tabular}{|c|c|c|c|c|c|c|c|c|c|}
\hline & \multirow[b]{2}{*}{ Coefficient } & \multicolumn{2}{|l|}{ Univariate } & \multicolumn{3}{|c|}{ Multivariate predictive } & \multicolumn{3}{|c|}{ Multivariate explanatory } \\
\hline & & $95 \% \mathrm{Cl}$ & $P$ values & Coefficient & $95 \% \mathrm{Cl}$ & $P$ values & Coefficient & $95 \% \mathrm{Cl}$ & $P$ values \\
\hline \multicolumn{10}{|l|}{ Treatment modalities } \\
\hline Any laser & 0.01 & -0.049 to 0.068 & 0.75 & & & & & & \\
\hline Electrocautery & 0.047 & 0.001 to 0.094 & 0.04 & & & & & & \\
\hline Argon plasma & 0.007 & -0.038 to 0.052 & 0.76 & & & & & & \\
\hline Cryorecanalisation & 0.081 & 0.030 to 0.133 & 0.002 & & & & & & \\
\hline Microdebrider & -0.004 & -0.1 & 0.88 & & & & & & \\
\hline Rigid 'coring' & 0.038 & -0.032 to 0.108 & 0.29 & & & & & & \\
\hline Dilation & -0.042 & -0.097 to 0.012 & 0.13 & & & & & & \\
\hline Stent at first procedure & -0.035 & -0.081 to 0.011 & 0.14 & & & & & & \\
\hline \multicolumn{10}{|l|}{ Technical success } \\
\hline Complete or partial & 0.003 & -0.068 to 0.073 & 0.94 & & & & & & \\
\hline Failed & $<$ ref $>$ & & & & & & & & \\
\hline \multicolumn{10}{|l|}{ Postprocedure treatment } \\
\hline Surgery & -0.058 & -0.170 to 0.054 & 0.31 & & & & & & \\
\hline Chemotherapy & 0.004 & -0.041 to 0.048 & 0.87 & & & & & & \\
\hline Radiation therapy & 0.004 & -0.040 to 0.048 & 0.87 & & & & & & \\
\hline
\end{tabular}

HRQOL of 0.65 utiles, a $\Delta$ utility-day-30 of +0.023 utiles and a $\Delta$ Borg-day-30 of $-0.9 .^{3}$ In AQuIRE, for every one unit increase in $\Delta$ Borg-day- $30, \Delta$ utility-day-30 changed by -0.020 utiles (ie, more dyspnoea, lower HRQOL). In this study, baseline HRQOL was 0.618 utiles, $\Delta$ utility-day-7 was +0.047 utiles, $\Delta$ Borg-day- 7 was -1.8 and for every one unit increase in $\Delta$ Borg-day- $7, \Delta$ utility-day-7 changed by -0.021 utiles. So in terms of the short-term impact of therapeutic bronchoscopy on dyspnoea and HRQOL, our findings are similar to AQuIRE. ${ }^{3}$ The present findings are also consistent with those in the literature, which demonstrate that for non-small cell lung cancer, utilities for health states for cancer-related outcome range from 0.70 (responding to therapy) to 0.47 (progressive disease) to 0.33 (end of life)..$^{28}$

The effect size observed in this study for short-term outcomes was somewhat greater for change in utility and dyspnoea than in AQuIRE, but the relationship between $\Delta$ Borg and $\Delta$ utility was similar. Part of the difference between studies may be due to the use of day-7 outcomes versus day-30 outcomes. We chose day-7 outcomes as a measure of the immediate impact of therapeutic bronchoscopy rather than the previously published day-30 based on what we learnt from AQuIRE. In AQuIRE, we found that many patients received additional treatments (eg, chemotherapy) within 30 days, which confounds the assessment of the impact of bronchoscopy on utility, since changes could be due to factors other than bronchoscopy. So the increased effect size observed in this study for relatively short-term outcomes is likely a combination of differences in timing of measurement, centrelevel variability and patient selection.

However, while knowledge of the determinants of short-term outcomes following therapeutic bronchoscopy for malignant central airway obstruction is useful, it is not sufficient. We need to be able to quantify long-term benefits as well. One of the key questions unanswered by AQuIRE was whether short-term improvements in dyspnoea and utility are maintained over time and how much do they impact quality-adjusted survival. This study adds to the existing body of knowledge by quantifying the long-term quality-adjusted survival of patients undergoing therapeutic bronchoscopy. Our findings suggest that long-term HRQOL per day of life following therapeutic bronchoscopy was significantly better than the prebronchoscopy baseline ( $\Delta$ utility-long-term +0.036 utiles per day of life).

This change in long-term HRQOL represents the aggregate of a multimodality approach, not just bronchoscopy (see online supplement e-table 3 ). However, much of the observed improvement is probably due to a sustained reduction in dyspnoea. This reduction in dyspnoea is initially achieved with bronchoscopy and is subsequently maintained over time. This is supported by our finding that the short-term impact of therapeutic bronchoscopy on dyspnoea ( $\Delta$ Borg-day-7) was strongly associated with short-term HRQOL changes ( $\Delta$ utility-day-7). Short-term term HRQOL changes were also strongly associated with longterm changes in HRQOL as measured by $\Delta$ utility-long-term (table 5 , adjusted $\mathrm{R}^{2}=0.59$ for $\Delta$ utility-day-7 impact on $\Delta$ utility-long-term). Since changes in utility from prebronchoscopy to 7 days postbronchoscopy are most likely due to the effects of therapeutic bronchoscopy rather than other treatments (eg, chemotherapy), the finding that $\Delta$ utility-day-7 explains $59 \%$ of the variance in long-term HRQOL suggests that the short-term benefits of therapeutic bronchoscopy are maintained over time and help drive improvements in long-term HRQOL.

Comparing therapeutic bronchoscopy as part of a multimodality approach with radiation therapy (RT) alone for malignant $\mathrm{CAO}$ is difficult because improvements in RT dosing and delivery limit the value of historical comparisons. In addition, there is very little data on RT for malignant CAO. However, historical data from when therapeutic bronchoscopy was not available can provide some useful insights provided we keep these limitations in mind. ${ }^{4}$ A study from the Mayo Clinic found that laser resection for malignant CAO improved survival (40\% mortality at 7 months and $72 \%$ at 1 year) as compared with historical controls that received radiation $(76 \%$ mortality at 4 months and $100 \%$ mortality by 7 months). ${ }^{29}$ The Cleveland Clinic published data on Nd:YAG laser/RT versus historical controls receiving RT and found better survival with bronchoscopy when the airway obstruction was emergent ( 267 vs 150 days, $p=0.04$ ). ${ }^{30}$ In the same series, taking both emergent and non-emergent cases, there was no survival difference (YAG 304 days vs RT 253 days, $p=0.17)$. A study of mechanically ventilated patients with 
Table 6 Factors associated with time to death, predictive Cox model

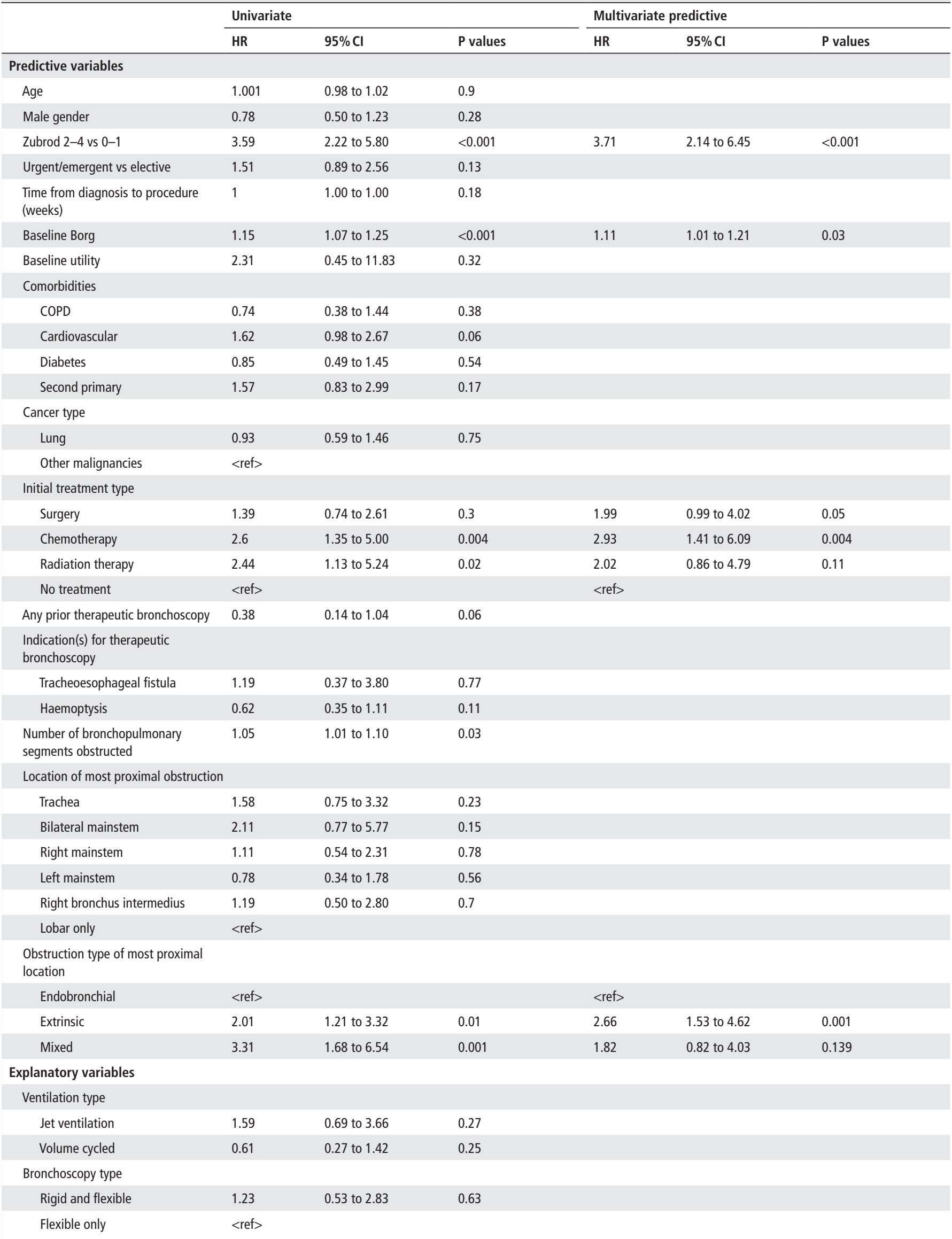


Table 6 Continued

\begin{tabular}{|c|c|c|c|c|c|c|}
\hline & \multicolumn{3}{|c|}{ Univariate } & \multicolumn{3}{|c|}{ Multivariate predictive } \\
\hline & HR & $95 \% \mathrm{Cl}$ & $P$ values & HR & $95 \% \mathrm{Cl}$ & $P$ values \\
\hline \multicolumn{7}{|l|}{ Treatment modalities } \\
\hline Any laser & 0.48 & 0.24 to 0.95 & 0.04 & & & \\
\hline Electrocautery & 0.67 & 0.40 to 1.10 & 0.11 & & & \\
\hline Argon plasma & 0.85 & 0.54 to 1.33 & 0.48 & & & \\
\hline Cryorecanalisation & 0.73 & 0.41 to 1.31 & 0.29 & & & \\
\hline Microdebrider & 0.78 & 0.46 to 1.32 & 0.35 & & & \\
\hline Rigid 'coring' & 0.79 & 0.38 to 1.64 & 0.52 & & & \\
\hline Dilation & 1.42 & 0.83 to 2.43 & 0.2 & & & \\
\hline \multicolumn{7}{|l|}{ Stent type placed } \\
\hline Aero & 1.17 & 0.50 to 2.73 & 0.71 & & & \\
\hline Y-Stent & 0.8 & 0.33 to 1.94 & 0.63 & & & \\
\hline \multicolumn{7}{|l|}{ Technical success } \\
\hline Complete or partial & 0.69 & 0.34 to 1.38 & 0.3 & & & \\
\hline Failed & $<$ ref $>$ & & & & & \\
\hline \multicolumn{7}{|l|}{ Postprocedure treatment } \\
\hline Chemotherapy & 0.54 & 0.34 to 0.84 & 0.01 & & & \\
\hline Radiation therapy & 0.86 & 0.55 to 1.35 & 0.52 & & & \\
\hline \multicolumn{7}{|l|}{ Time-varying covariates } \\
\hline Presence of stent & 2.47 & 1.56 to 3.91 & $<0.001$ & & & \\
\hline Utility & 0.002 & 0.0003 to 0.011 & $<0.001$ & & & \\
\hline Borg score & 1.22 & 1.14 to 1.31 & $<0.001$ & & & \\
\hline Lower respiratory tract infection & 2.35 & 0.72 to 7.63 & $<0.001$ & & & \\
\hline
\end{tabular}

Utility range is from 0 to 1 . So for a 0.01 unit increase in utility as a time-varying covariate, the HR is $0.002^{\wedge} 0.01=0.94$. So for each 0.01 increase in utility, the hazard rate of death decreases by $6 \%$. Note that this is exponential, so for a 0.1 increase in utility, the hazard rate of death does not decrease by $60 \%$. Rather it is $0.002 \wedge 0.1=0.54$. So an increase in utility of 0.1 is associated with a $46 \%$ decrease in the hazard rate of death.

malignant central airway obstruction found that those with successful reopening of the airway did better and received additional chemo-RT after successful extubation. ${ }^{31}$ Unfortunately, none of these studies measured quality-adjusted survival.

We believe that quantifying the impact of therapeutic bronchoscopy on dyspnoea and quality-adjusted survival can help inform clinical decision making. We found that the impact of bronchoscopic intervention is maximal early on (ie, $\Delta$ utility-day- $7+0.047$ utiles), but as the disease progresses and side effects set in HRQOL is impacted ( $\Delta$ utility-long-term +0.036 utiles per day of life). A conservative assumption regarding therapeutic bronchoscopy is that it does not extend duration of life at all, it does not prevent any postobstructive pneumonias, and its only benefit is that it improves HRQOL by alleviating dyspnoea related to $\mathrm{CAO}$ obstruction. The initial $\Delta$ utility-day-7 provides an upper limit estimate of the impact of therapeutic bronchoscopy on HRQOL based on these assumptions. Over the long-term, this estimate may be too high-time and disease will mitigate the beneficial effects, so $\Delta$ utility-long-term provides a more conservative assessment of benefit. Since this is not a randomised controlled trial, we cannot provide a more precise assessment of the impact of therapeutic bronchoscopy as compared with the alternative of not doing bronchoscopy. While such a randomised controlled trial would be informative, it would not be ethical, and as such we believe using $\Delta$ utility-long-term provides a practical if not perfect estimate of the effect of therapeutic bronchoscopy on HRQOL. Given these limitations, what we can say with confidence is that HRQOL per day of life postbronchoscopy is on average better than it was prebronchoscopy and this effect is maintained over time.

Because physicians do not often deal with utility, it can be difficult for clinicians to interpret how large an effect size this represents. So for clinical practice it can be helpful to put utility numbers into clinical context in order to calibrate judgement. So how much does a change of +0.036 utiles per day of life represent? First, let us remember that mean baseline utility was 0.618 utiles, so this represents a $5.8 \%$ improvement. Since we are evaluating quality-adjusted survival, this improvement in HRQOL is equivalent to living 5.8\% longer if HRQOL were to remain at baseline levels.

Another way to gain clinical context is to compare this effect with the effect of more common interventions in similar populations. However, comparing the impact of interventions between very different populations using QALYs is not always valid (see online supplement). ${ }^{32-35}$ Care must be taken when choosing a comparator population and intervention. Given these limitations, the most analogous population for which there is data is probably patients with malignant pleural effusions (MPE).${ }^{15}$ Both populations have metastatic cancer, both have similar life expectancies and in both cases the palliative intervention is aimed at dyspnoea relief. Unlike malignant CAO, MPE is a very common problem for many pulmonologists, so a comparison can provide context to the utility measures being reported. In a prospective observational study of 266 patients undergoing indwelling pleural catheter (IPC) placement for MPE, HRQOL at 1 month post-IPC increased compared with baseline by +0.023 utiles. $^{15}$ 
Table 7 Factors associated with time to death, multivariate explanatory extended Cox models

\begin{tabular}{|c|c|c|c|c|c|c|}
\hline & \multicolumn{3}{|c|}{ Cox model } & \multicolumn{3}{|c|}{ Extended Cox model } \\
\hline & HR & $95 \% \mathrm{Cl}$ & $P$ values & HR & $95 \% \mathrm{Cl}$ & $P$ values \\
\hline \multicolumn{7}{|l|}{ Predictive variables } \\
\hline Zubrod 2-4 vs 0-1 & 4.4 & 2.55 to 7.60 & $<0.001$ & 3.02 & 1.83 to 5.00 & $<0.001$ \\
\hline $\begin{array}{l}\text { Time from diagnosis to } \\
\text { procedure (weeks) }\end{array}$ & 0.998 & 0.996 to 0.9996 & 0.02 & & & \\
\hline $\begin{array}{l}\text { Comorbidities: } \\
\text { cardiovascular }\end{array}$ & 1.76 & 1.00 to 3.08 & 0.05 & & & \\
\hline \multicolumn{7}{|l|}{ Initial treatment type } \\
\hline Surgery & 3.54 & 1.60 to 7.81 & 0.002 & & & \\
\hline Chemotherapy & 2.98 & 1.47 to 6.05 & 0.002 & & & \\
\hline Radiation therapy & 2.62 & 1.15 to 5.99 & 0.02 & & & \\
\hline No treatment & $<$ ref $>$ & & & & & \\
\hline \multicolumn{7}{|l|}{$\begin{array}{l}\text { Obstruction type of most } \\
\text { proximal location }\end{array}$} \\
\hline Endobronchial & $<$ ref $>$ & & & & & \\
\hline Extrinsic & 2.63 & 1.54 to 4.50 & $<0.001$ & & & \\
\hline Mixed & 2.35 & 1.13 to 4.86 & 0.02 & & & \\
\hline \multicolumn{7}{|l|}{ Explanatory variables } \\
\hline \multicolumn{7}{|l|}{ Postprocedure treatment } \\
\hline Chemotherapy & 0.42 & 0.26 to 0.69 & 0.001 & 0.51 & 0.32 to 0.81 & 0.004 \\
\hline \multicolumn{7}{|l|}{ Time-varying covariates } \\
\hline Utility & & & & 0.003 & 0.001 to 0.02 & $<0.001$ \\
\hline $\begin{array}{l}\text { Lower respiratory tract } \\
\text { infection }\end{array}$ & & & & 3.79 & 1.13 to 12.71 & 0.03 \\
\hline
\end{tabular}

So as a rough approximation, the mean change in HRQOL immediately following therapeutic bronchoscopy at day-7 is double that seen with drainage of a MPE $(+0.047 \mathrm{vs}+0.023$ utiles, respectively). Over the long-term, the impact of bronchoscopy is roughly one-and-a-half times as much as the improvement seen with an IPC.

This improvement in HRQOL must be weighed against the risks. While there were no fatal procedural complications in this study, the overall rate of fatal procedural complications reported in AQuIRE was $0.5 \% .^{27}$ The overall risk-benefit ratio of therapeutic bronchoscopy is very favourable if we use $0.5 \%$ as our estimate of fatal procedural complications and consider $\Delta$ utility-long-term as roughly a $5.8 \%$ improvement over baseline.

Although these findings are useful, it is important to recognise the limitations of the data. This was a single-centre prospective observational study. The generalisability of the results to other centres may be limited. There is significant heterogeneity between centres in terms of methods of therapeutic bronchoscopy, complication rates and 30-day mortality. ${ }^{327}$ The impact of therapeutic bronchoscopy observed in this study may vary from that of other centres depending on patient referral patterns, patient selection and bronchoscopic techniques. In addition, as with any long-term longitudinal study, imputation for missing data can be a problem. We prespecified the LOCF method based on prior studies, ${ }^{15}$ but the LOCF methodology can be prone to bias under certain conditions (see online supplement). ${ }^{36} 37$ However, because we sampled so frequently (ie, monthly) the intrapatient variation between months in utility was low, such that whether we used an LOCF or a carry-backwards imputation method, this did not change the results. Note that the limitations of imputation in this study only apply to the long-term outcomes, not the day-7 outcomes.
In conclusion, this study supports and extends the findings of the AQuIRE group. The data suggest that when baseline dyspnoea is more severe there is greater potential for therapeutic bronchoscopy to have a meaningful impact on utility. ${ }^{3}$ The impact of bronchoscopic interventions, especially when done as part of multimodality treatment, are such that the improvements in dyspnoea and utility are likely to be sustained for most patients. While immediate and longterm complications are significant, given the observed rates in this trial and other large series, ${ }^{1-14}$ the risk-benefit ratio can be considered favourable, provided the malignant CAO is causing significant dyspnoea that is contributing to the patient's poor HRQOL. Future studies using more formal decision analysis techniques will be needed to further clarify the decision thresholds and trade-offs involved. The magnitude of the change in HRQOL following therapeutic bronchoscopy is roughly equivalent to a $5.8 \%$ improvement in quality-adjusted survival.

Acknowledgements The authors would like to thank Dr Xiudong Lei, PhD, biostatistics department for her help with power calculations and design and Dr Liang Li for his help with imputation analysis.

Contributors DEO was the principal investigator (PI) for this study and was involved in project oversight, organisation, data collection and auditing, statistical analysis and manuscript writing. PO did the statistical analysis and was involved in manuscript writing. HBG, LD, CAJ, GAE and RFC were involved in data collection and auditing, and manuscript writing. LN contributed to data collection, auditing and review.

Funding This study was funded by NIH/NCl biostatistic core (P30CA016672), biostatistics core, at the University of Texas, MD Anderson Cancer Center and Institutional Research Grant from MD Anderson Cancer Center.

Competing interests None declared.

Patient consent Obtained. 
Ethics approval Institutional review board approval was obtained from The University of Texas MD Anderson IRB Committee 4.

Provenance and peer review Not commissioned; externally peer reviewed.

\section{REFERENCES}

1 Ernst A, Simoff M, Ost D, et al. Prospective risk-adjusted morbidity and mortality outcome analysis after therapeutic bronchoscopic procedures: results of a multiinstitutional outcomes database. Chest 2008;134:514-9.

2 Casal RF, Iribarren J, Eapen G, et al. Safety and effectiveness of microdebrider bronchoscopy for the management of central airway obstruction. Respirology 2013;18:1011-5.

3 Ost DE, Ernst A, Grosu HB, et al. Therapeutic bronchoscopy for malignant central airway obstruction: success rates and impact on dyspnea and quality of life. Chest 2015;147:1282-98.

4 Ernst A, Feller-Kopman D, Becker HD, et al. Central airway obstruction. Am J Respir Crit Care Med 2004;169:1278-97.

5 Seijo LM, Sterman DH. Interventional pulmonology. N Eng/ J Med 2001;344:740-9.

6 Husain SA, Finch D, Ahmed M, et al. Long-term follow-up of ultraflex metallic stents in benign and malignant central airway obstruction. Ann Thorac Surg 2007;83:1251-6.

7 Razi SS, Lebovics RS, Schwartz G, et al. Timely airway stenting improves survival in patients with malignant central airway obstruction. Ann Thorac Surg 2010;90:1088-93.

8 Oviatt PL, Stather DR, Michaud G, et al. Exercise capacity, lung function, and quality of life after interventional bronchoscopy. J Thorac Oncol 2011;6:38-42.

9 Furukawa K, Ishida J, Yamaguchi G, et al. The role of airway stent placement in the management of tracheobronchial stenosis caused by inoperable advanced lung cancer. Surg Today 2010;40:315-20.

10 Amjadi K, Voduc N, Cruysberghs Y, et al. Impact of interventional bronchoscopy on quality of life in malignant airway obstruction. Respiration 2008;76:421-8.

11 Bolliger CT, Breitenbuecher A, Brutsche M, et al. Use of studded Polyflex stents in patients with neoplastic obstructions of the central airways. Respiration 2004;71:83-7.

12 Bolliger CT, Sutedja TG, Strausz J, et al. Therapeutic bronchoscopy with immediate effect: laser, electrocautery, argon plasma coagulation and stents. Eur Respir J 2006;27:1258-71.

13 Bolliger CT, Mathur PN, Beamis JF, et al. ERS/ATS statement on interventional pulmonology. European Respiratory Society/American Thoracic Society. Eur Respir J 2002;19:356-73.

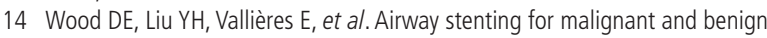
tracheobronchial stenosis. Ann Thorac Surg 2003;76:167-74.

15 Ost DE, Jimenez CA, Lei $X$, et al. Quality-adjusted survival following treatment of malignant pleural effusions with indwelling pleural catheters. Chest 2014; 145:1347-56

16 Deslée G, Mal H, Dutau H, et al. Lung volume reduction coil treatment vs usual care in patients with severe emphysema: The REVOLENS Randomized Clinical Trial. JAMA 2016;315:175-84.

17 Rawlins MD, Culyer AJ. National institute for clinical excellence and its value judgments. BMJ 2004;329:224-7.

18 Weinstein MC, Siegel JE, Gold MR, et al. Recommendations of the panel on costeffectiveness in health and medicine. JAMA 1996;276:1253-8.
19 Siegel JE, Torrance GW, Russell LB, et al. Guidelines for pharmacoeconomic studies. recommendations from the panel on cost effectiveness in health and medicine. panel on cost effectiveness in health and medicine. Pharmacoeconomics 1997:11:159-68.

20 Siegel JE, Weinstein MC, Russell LB, et al. Recommendations for reporting costeffectiveness analyses. panel on cost-effectiveness in health and medicine. JAMA 1996;276:1339-41.

21 Atkins D, DiGuiseppi CG. Broadening the evidence base for evidence-based guidelines. A research agenda based on the work of the U.S. Preventive Services Task Force. Am J Prev Med 1998;14:335-44.

22 Eapen GA, Shah AM, Lei X, et al. Complications, consequences, and practice patterns of endobronchial ultrasound-guided transbronchial needle aspiration: Results of the AQuIRE registry. Chest 2013;143:1044-53.

23 Yarmus LB, Akulian J, Lechtzin N, et al. Comparison of 21-gauge and 22-gauge aspiration needle in endobronchial ultrasound-guided transbronchial needle aspiration: results of the american college of chest physicians quality improvement registry, education, and evaluation registry. Chest 2013;143:1036-43.

24 Ost DE, Ernst $A$, Lei $X$, et al. Diagnostic yield of endobronchial ultrasound-guided transbronchial needle aspiration: results of the AQuIRE Bronchoscopy Registry. Chest 2011;140:1557-66.

25 Harris PA, Taylor R, Thielke R, et al. Research electronic data capture (REDCap)--a metadata-driven methodology and workflow process for providing translational research informatics support. J Biomed Inform 2009;42:377-81.

26 Brazier J, Roberts J, Deverill M. The estimation of a preference-based measure of health from the SF-36. J Health Econ 2002;21:271-92.

27 Ost DE, Ernst A, Grosu HB, et al. Complications following therapeutic bronchoscopy for malignant central airway obstruction: results of the aquire registry. Chest 2015:148:450-71.

28 Nafees B, Stafford M, Gavriel S, et al. Health state utilities for non small cell lung cancer. Health Qual Life Outcomes 2008;6:84.

29 Brutinel WM, Cortese DA, McDougall JC, et al. A two-year experience with the neodymium-YAG laser in endobronchial obstruction. Chest 1987:91:159-65.

30 Desai SJ, Mehta AC, VanderBrug Medendorp S, et al. Survival experience following $\mathrm{Nd}$ :YAG laser photoresection for primary bronchogenic carcinoma. Chest 1988:94:939-44.

31 Stanopoulos IT, Beamis JF, Martinez FJ, et al. Laser bronchoscopy in respiratory failure from malignant airway obstruction. Crit Care Med 1993;21:386-91.

32 Carr AJ, Higginson IJ. Are quality of life measures patient centred? BMJ 2001;322:1357-60.

33 Dorman S, Jolley C, Abernethy A, et al. Researching breathlessness in palliative care: consensus statement of the national cancer research institute palliative care breathlessness subgroup. Palliat Med 2009;23:213-27.

34 Higginson IJ, Carr AJ. Measuring quality of life: Using quality of life measures in the clinical setting. BMJ 2001;322:1297-300.

35 Paci E, Miccinesi G, Toscani F, et al. Quality of life assessment and outcome of palliative care. J Pain Symptom Manage 2001;21:179-88.

36 Salim A, Mackinnon A, Christensen H, et al. Comparison of data analysis strategies for intent-to-treat analysis in pre-test-post-test designs with substantial dropout rates. Psychiatry Res 2008;160:335-45.

37 Molnar FJ, Hutton B, Fergusson D. Does analysis using "last observation carried forward" introduce bias in dementia research? CMAJ 2008;179:751-3. 